\title{
Adoption of Circular Economy concepts and practices by Portuguese Citizens and Companies
}

\author{
Luis Miguel FONSECA \\ ISEP -P. Porto and CIDEM R\&D, Porto, Portugal \\ Imf@isep.ipp.pt \\ José Pedro DOMINGUES \\ ISEP-IPP, Porto, Portugal \\ jpd@isep.ipp.pt
}

\begin{abstract}
The concept of Circular Economy is an emerging topic and the European Union has established a European Circular Economy Strategy in 2015. Although this concept originates from Europe, there is also an increased attention to the Circular Economy in China and the country has implemented regulatory controls in that regard. The scientific interest on this issue has been increasing and a great deal of research articles has been published in the soundest scientific journals recently. The concept of Circular Economy aims to address the need to pursue economic growth, while protecting the environment (including existing resource limitations and pollution prevention), and paying attention to societal and people needs and expectations. The adoption of Circular Economy can generate considerable tangible and intangible benefits such as new opportunities for co-operation, access to markets and innovation of products and services and, simultaneously, improving the environmental performance and mitigating the risks of resource scarcity. This creates value for the companies and their stakeholders and contributes to enduring success. To assess if the Portuguese citizens and companies support and adopt a "Circular Economy behavior", an online survey was carried out amongst ISEP - P. Porto population, yielding more than 200 valid responses $(65 \%$ of the total responses were provided by students). Based on the survey outputs (assessment supported in a 5 point Likert type scale), the following conclusions can be drawn: Most respondents agree that it is beneficial both for the environment and the economy the adoption of production systems based on used products and parts reuse and recycling; There is also agreement that the selective collection of waste should be the base to develop new products and there is significant support for a "zero waste economy" in which all used products or materials are reused or recycled. However, the respondents consider that the Portuguese citizens do not always segregate and deposit their waste in the appropriate waste containers and the same applies to companies that do not segregate and manage their waste adopting a systematically environmentally responsible approach. Moreover, they consider that the Portuguese legislation only mildly supports the adoption, both from citizens and companies, of environmental friendly practices. These conclusions reinforce the need to strengthen Circular Economy concepts and approaches within the Portuguese government, citizens, and companies.
\end{abstract}

Keywords: circular economy, sustainability, closed-loop economy, sustainable consumption, change, engineering students.

\section{Introduction}

The concept of Circular Economy (CE) has gained significant attention since the late 90s (Pearce and Tuner, 1990) with its innovative approach of addressing the relationship between business and the environment, aiming at improving sustainable production and overall consumption. In addition, the companies' awareness regarding all relevant stakeholders (their needs and expectations) increased in the last decades (Domingues et al., 
2015). The rationale and the underlying philosophy supporting the CE approach considers that many by-products and wastage from processes and consumers can be a direct or indirect source of inputs for other processes, so they may be partially recovered minimizing resource scarcity and over exploitation. To fully benefit from these opportunities, closedloop materials and energy flows should be adopted and implemented, across a wide range of sectors in order to reduce energy consumption, using natural resources more efficiently and improving the control of both the production and consumption environmental impacts. CE has been discussed as a suitable approach aiming at the leverage of the competitiveness of industrial processes and systems and at the systemic development of strategies to foster the decoupling of economic growth from resource availability and other environmental constraints. The effective implementation of CE implies the adoption of novel business models that require increased responsibility and awareness from both the consumers and organizations and, concurrently, the adoption of new consumption patterns, compatible with CE concepts and approaches.

This research aims at the evaluation of the perceptions of ISEP - P. Porto population concerning CE benefits and the support for CE practices by the Portuguese citizens and companies. Following the literature review, a quantitative research by means of an online survey was carried out amongst ISEP- P. Porto population, yielding more than 200 valid responses, encompassing students (65\% of the total responses), professors and other employees. According to the results, $\mathrm{CE}$ is indeed beneficial both to the economy and to the environment. However, according to the sampled population (ISEP- P. Porto), Portuguese citizens do not always segregate and deposit their waste in the appropriate waste containers. Additionally, the respondents perceive that companies do not systematically segregate and manage their waste adopting the most responsible environmental best practices. Furthermore, most of the respondents consider that the Portuguese legislation only mildly supports the adoption, both from citizens and companies, of environmental friendly practices. An analysis of the results by place of residence shows they are similar for the different populations within Porto Metropolitan area. These conclusions reinforce the need to strengthen the concepts and the adoption of CE approaches within the Portuguese government, citizens, and companies considering that the transformation towards CE needs to overcome the citizens and companies' resistance to change and, concurrently, the effective adoption of new behavior patterns and business models.

\section{Literature review}

We live in an interconnected digital world characterized by increased mobility and access to information, and we must deal with a range of global issues, such as environmental protection, health improvement, knowledge economy and intellectual capital (Bratianu, 2009), and fight against poverty, which need new knowledge strategies (Bratianu and Bolisani, 2015). Stakeholders demand that companies adopt more transparent and responsible approaches, aiming at the holistic achievement of economic growth, social progress, equity, respect, and awareness for the environment. To succeed in this challenging environment, organizations should monitor the organizational context, identify risks and opportunities, and manage change effectively (Fonseca and Domingues, 2017). Moreover, throughout the last decade an increasing amount of companies adopted environmental management systems (and other management subsystems), such as the ISO 
14001 International Standard aiming at improving their environmental performance, preventing pollution, and assuring the compliance with the regulatory requirements and applicable legislation (Domingues et al., 2017; Fonseca, 2015).

Ultimately, $\mathrm{CE}$ is a new paradigm that aims to conciliate economic and environmental performance. It is based on the concept of improved management of resources (Ellen MacArthur Foundation, 2016) by relying on closed loops, regenerative, and PICBE $\mid 376$ restorative physical and economic cycles, where products and raw materials retain their physical characteristics and by (re)using them as much as possible. CE creates new opportunities for co-operation, access to markets and innovation of products and services while minimizing negative impacts, fostering a sustainable and enduring economic growth. It creates tangible and intangible benefits for companies and their stakeholders, enhancing firms' competitiveness and mitigating risks, without endangering the environment and causing resources scarcity. CE is receiving increasing attention worldwide to overcome the current production and consumption model based on continuous growth and increasing resource throughput (Ghisellini et al., 2016). CE calls for the synergic contribution of several areas of expertise (Ghisellini et al., 2016; Heshmati, 2016; Lieder and Rashid, 2016; Murray et al., 2017; Sauvé et al., 2016) such as environmental studies, process engineering, biology, ecology, sociology, management, economics, territorial and urban planning, regulations, across a wide range of activity sectors (Bruce et al., 2004; Kanbur, 2002). In line with these views, the European Union considers CE as a primary goal for research and innovation policies at the firm level (European Commission, 2015; European Environmental Agency, 2016). CE has also been addressed in the last two 'Five Year Plans' drawn up by the Chinese government (Zhijun and Nailing, 2007), and is being operationalized in China. However, as the conceptualization and implementation of CE is relatively recent, there are some tensions and shortcomings related to its adoption and use namely: the implication of increased consumers and organizations responsibility and awareness, and the adoption of new consumption patterns, compatible with CE concepts and approaches (Murray et al., 2017). These new consumption patterns are based on new thinking patterns (Bratianu, 2007).A great deal of research studies report how supportive of CE are consumers in some specific countries, such as Romania (Lakatos et al., 2016) and the level of firms' awareness and patterns behavior throughout the development of CE in China (Yong and Bai, 2016). However, to the best of our knowledge, these types of studies have not been carried out in Portugal, and it is the purpose of this research to address this knowledge gap.

\section{Methodology}

Since CE is a relatively new concept, a research plan was designed and carried out amongst ISEP - P. Porto population, to assess their views and support of CE practices. Following the literature review and the definition of the research objectives, an email was sent to ISEP - P. Porto population in July 2017, asking for a participation in an online survey (Figure 1). The survey encompassed several initial questions aimed at the characterization of the respondents and 9 questions to assess the level of support and adoption of CE in Portugal. 


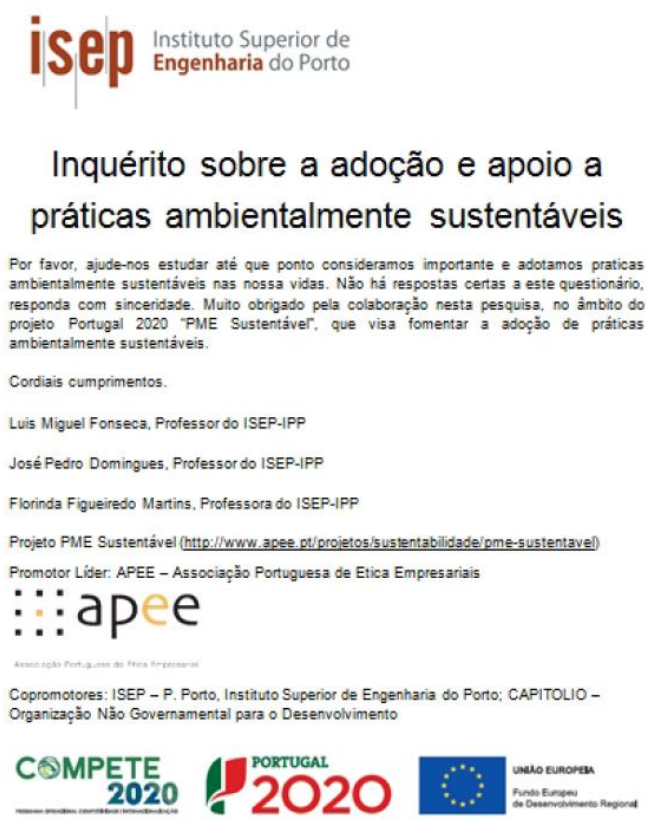

PICBE | 377

Figure 1. Screen copy of survey cover message

Source: Authors' own research.

The survey yielded 208 valid responses (3.5\% response rate) and a 5-point agreement Likert-type scale was adopted (Figure 2).

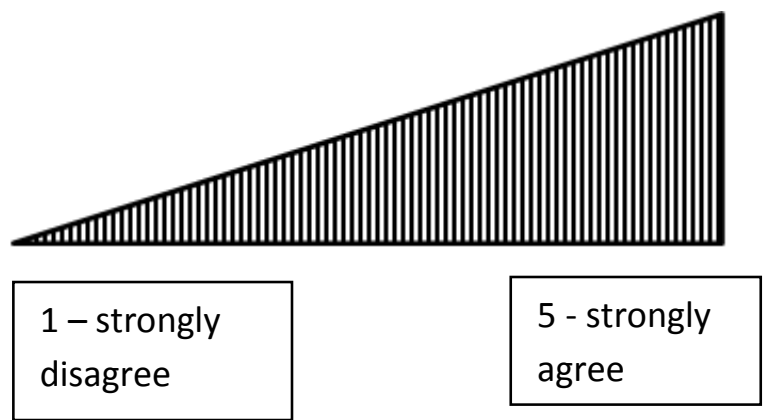

Figure 2. Adopted Likert scale

Source: Authors' own processing.

\section{Results and discussions}

Considering the respondents' gender, 59\% were male and 41\% female (Figure 3) and 81\% were not committed (Figure 4). 


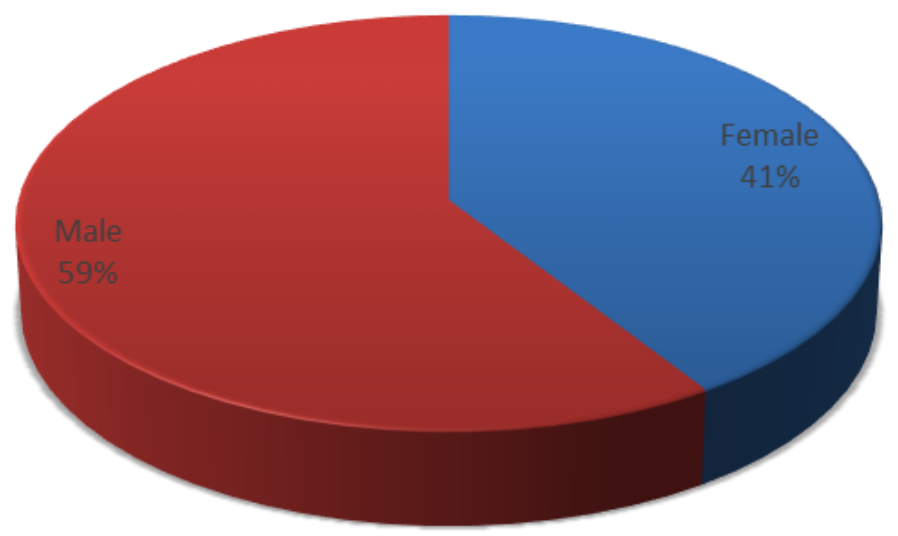

PICBE | 378

a Female $\mathbf{a}$ Male

Figure 3. Respondents' gender distribution

Source: Authors' own research.

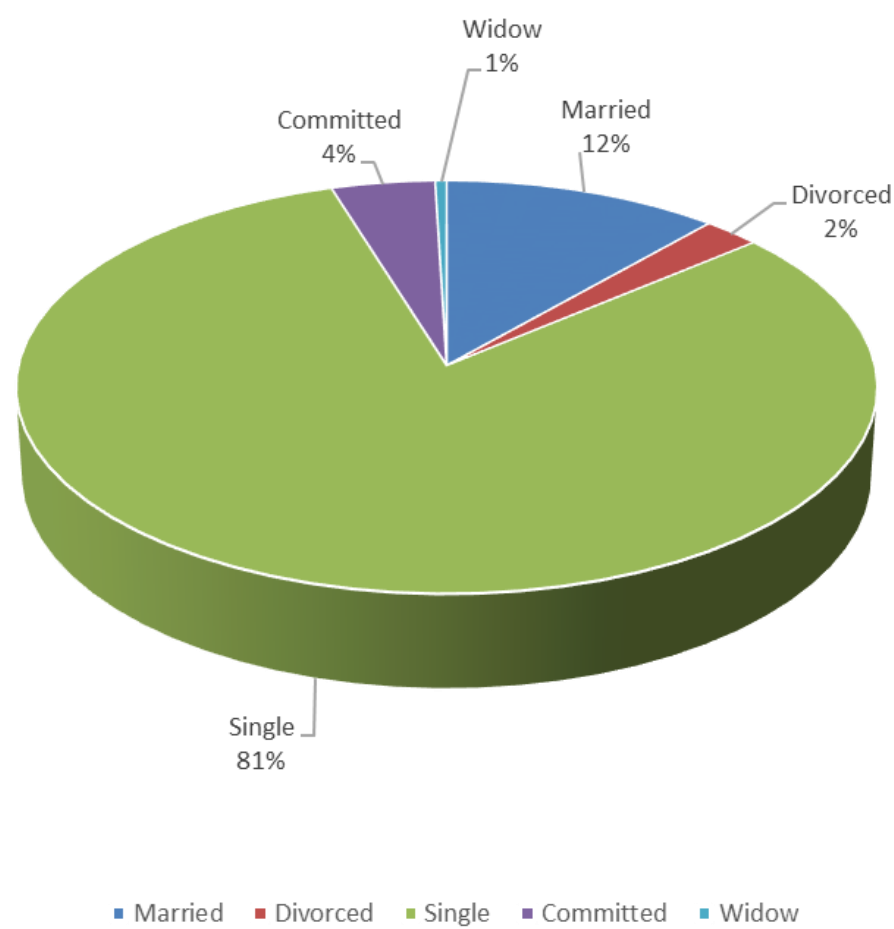

Figure 4. Respondents' civil status

Source: Authors' own research.

Students accounted for $65 \%$ of total responses and 34\% were entrepreneurs or employed (Figure 5). Concerning the academic qualifications, 56\% of the respondents held 
a Bachelor degree and 28\% held High School qualifications (still attending BSc courses) (Figure 6).

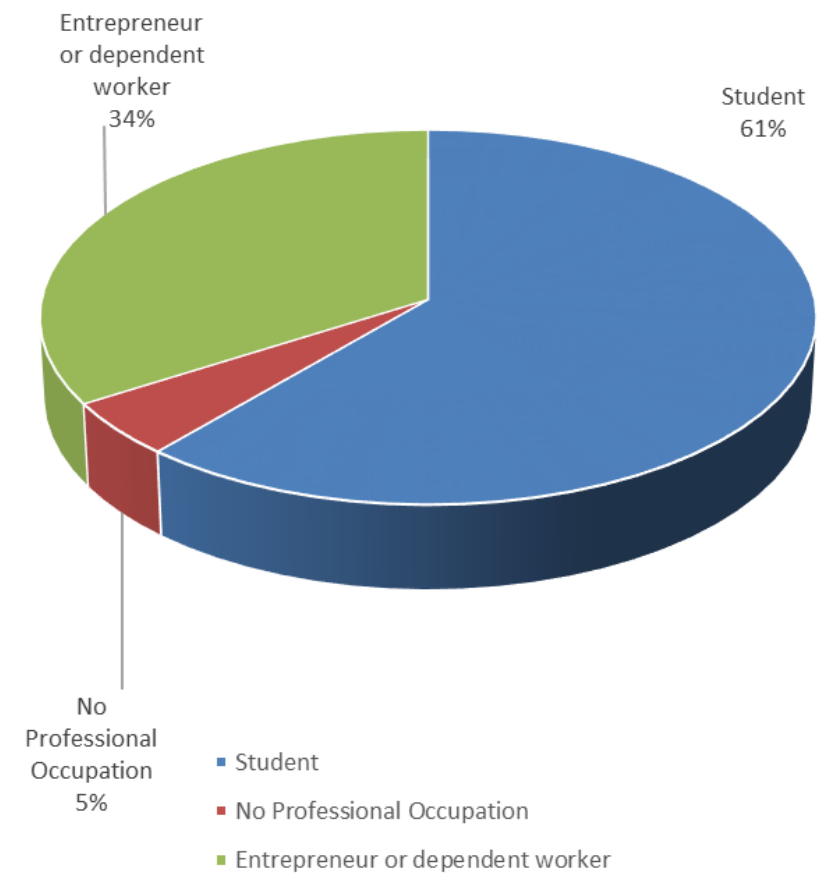

PICBE | 379

Figure 5. Respondents' professional status

Source: Authors' own research.

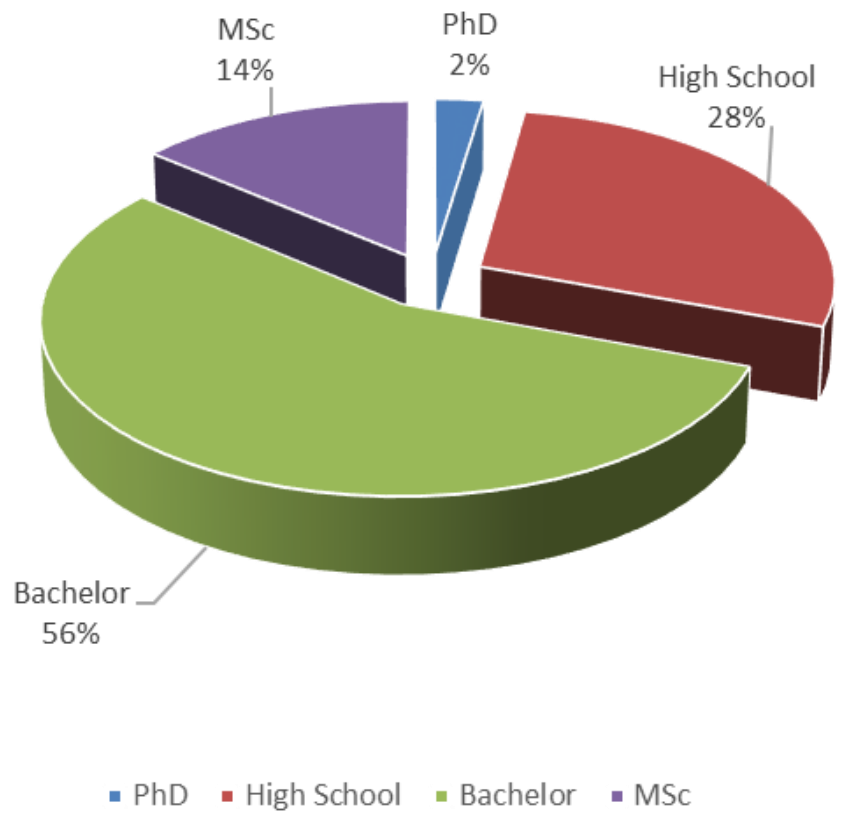

Figure 6. Respondents' qualifications

Source: Authors' own research. 
The survey response rate was less than expected from similar studies (Nulty, 2008). Due to this fact, a great deal of effort was devoted to assess the representation of the sample results. The analysis of the survey results suggests that it matches, i.e., properly represents the population, since the distribution by gender, qualifications, civil status, and students' qualification is consistent with the population. "Wave analysis" was also adopted to compare the results from late respondents and early respondents (Armstrong and Overton, 1977): the results collected throughout the four consecutive weeks (data collection period) show no significant differences, which supports the assumption that non-respondents' (absent responses) should be like those of the respondents, minimizing possible nonrespondents bias error. The survey response rate (lower than expected) might also be explained due to exam period followed by summer holidays. The descriptive statistics are summarized in Table 1.

Table 1. Respondents support for $\mathrm{CE}$ and perception of CE best practices adoption by Portuguese citizens and companies

\begin{tabular}{|c|c|c|c|}
\hline Item & Mean & Standard Deviation & Result \\
\hline $\begin{array}{l}\text { G.3.1. Do you agree that it is } \\
\text { beneficial to the economy the } \\
\text { adoption of production } \\
\text { systems based on reused } \\
\text { products and parts? }\end{array}$ & 4,11 & 0,87 & Positive \\
\hline $\begin{array}{l}\text { G3.1.2. Do you agree that it is } \\
\text { beneficial to the environment } \\
\text { the adoption of production } \\
\text { systems based on reused } \\
\text { products and parts? }\end{array}$ & 4,44 & 0,65 & Positive \\
\hline $\begin{array}{l}\text { G3.1.3. Do you agree that it is } \\
\text { beneficial to the economy the } \\
\text { adoption of production } \\
\text { systems based on recycling? }\end{array}$ & 4,21 & 0,80 & Positive \\
\hline $\begin{array}{l}\text { G3.1.4. Do you agree that it is } \\
\text { beneficial to the environment } \\
\text { the adoption of production } \\
\text { systems based on recycling? }\end{array}$ & 4,50 & 0,63 & Positive \\
\hline $\begin{array}{l}\text { G3.1.5 Do you agree that } \\
\text { selective waste collection } \\
\text { should be the basis to } \\
\text { produce new products? }\end{array}$ & 4,26 & 0,77 & Positive \\
\hline $\begin{array}{l}\text { G3.1.6 Do you agree with the } \\
\text { adoption of practices } \\
\text { towards a "zero waste } \\
\text { economy" where all the } \\
\text { materials and products are } \\
\text { reused and/or recycled? }\end{array}$ & 4,09 & 0,95 & Positive \\
\hline $\begin{array}{l}\text { G3.1.7. Do you agree that } \\
\text { most Portuguese citizens } \\
\text { deposit their waste in the } \\
\text { appropriate containers? }\end{array}$ & 2,59 & 0,85 & Fair \\
\hline $\begin{array}{l}\text { G3.1.8. Do you agree that } \\
\text { most Portuguese companies } \\
\text { segregate and manage their }\end{array}$ & 2,67 & 0,87 & Fair \\
\hline
\end{tabular}

DOI: 10.2478/picbe-2018-0033, pp. 374-385, ISSN 2558-9652| Proceedings of the $12^{\text {th }}$ International Conference on Business Excellence 2018 


\begin{tabular}{|l|l|l|l|}
\hline $\begin{array}{l}\text { waste adopting the best } \\
\text { responsible practices? }\end{array}$ & & & \\
\hline $\begin{array}{l}\text { G3.1.9. Do you agree that the } \\
\text { Portuguese government } \\
\text { issues legislation that favors } \\
\text { the adoption by citizens and } \\
\text { companies of environmental } \\
\text { responsible practices? }\end{array}$ & 2,53 & 0,97 & fair \\
\hline Mean & & & \\
\hline
\end{tabular}

PICBE | 381

Figure 7 presents graphically the results of the 9 items assessed and presented in Table 1 highlighting the existence of two clusters, one including variables G3.1.1 to G.3.16 with mean responses greater than 4 , and another with variables g 3.1.7 to G3.1.9 with mean around 2.5 .

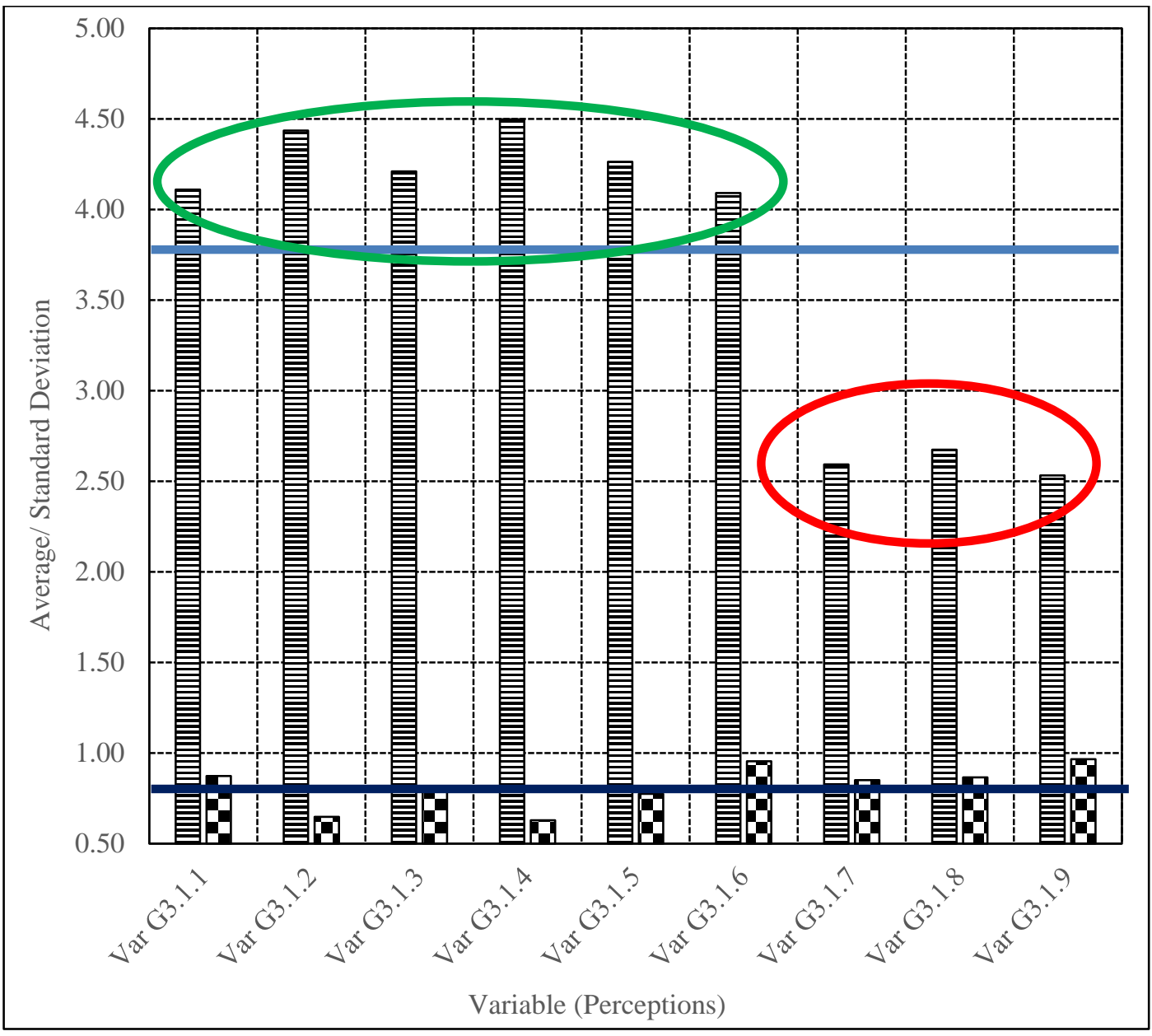

Figure 7. Respondents' support for CE and perception of CE adoption by Portuguese citizens and companies

Source: Authors' own research. 
ISEP - P. Porto population (Students, Professors, and Employees) are mostly from the Metropolitan Porto Area with a total population of 1, 76 million habitants (2011 census). Porto (238 thousands population) and its neighbor cities of V. Gaia, Maia and Matosinhos are the biggest cities, and many Students come from other smaller villages around Porto within a 50km radius. To assess if the place of residence can account for significant differences, in the support for the adoption of a zero-waste economy and its effective use by Portuguese citizens, the results of variables G3.1.6 (Do you agree with the adoption of practices towards a "zero waste economy" where all the materials and products are reused and/or recycled?) and G3.1.7 (G3.1.7. Do you agree that most Portuguese citizens deposit their waste in the appropriate containers?) have been calculated for the previous mentioned places. Figure 8 represents the distribution of the respondents by the areas where they live while Figure 9 presents the mean and standard deviation value for variables G3.1.6 (support for zero waste economy) and G.3.1.7 (Portuguese put waste in proper containers). The results are very similar for all the cities and places of residence, which is consistent with the fact there is an integrated waste management system in Porto Metropolitan area. However, it should be noted that while there is a significant respondent support for the adoption of a zero-waste economy, they consider that its adoption by Portuguese citizens (measured by the respondents' perception if waste is deposited in the appropriate containers?) is considerable lower.

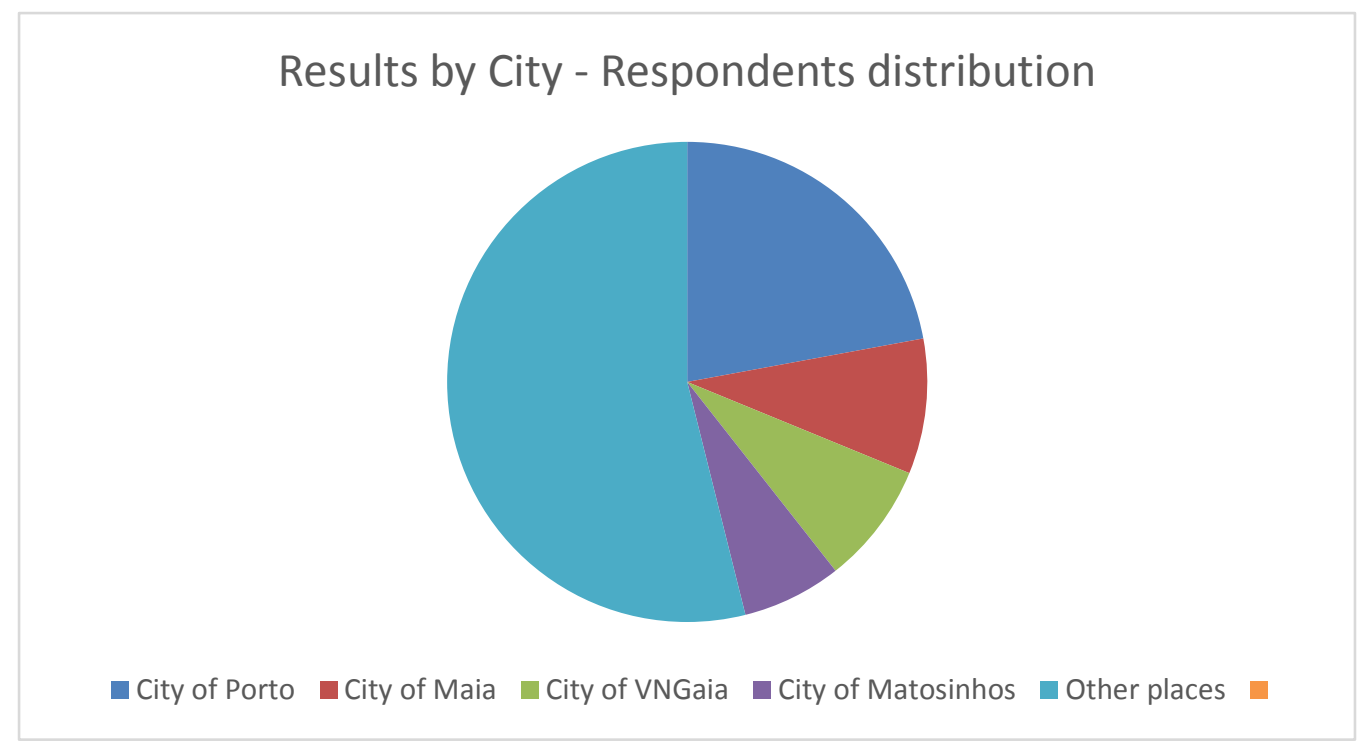

Figure 8. Respondents' distribution by place of residence

Source: Authors' own research. 


\section{Results by City - Mean values}

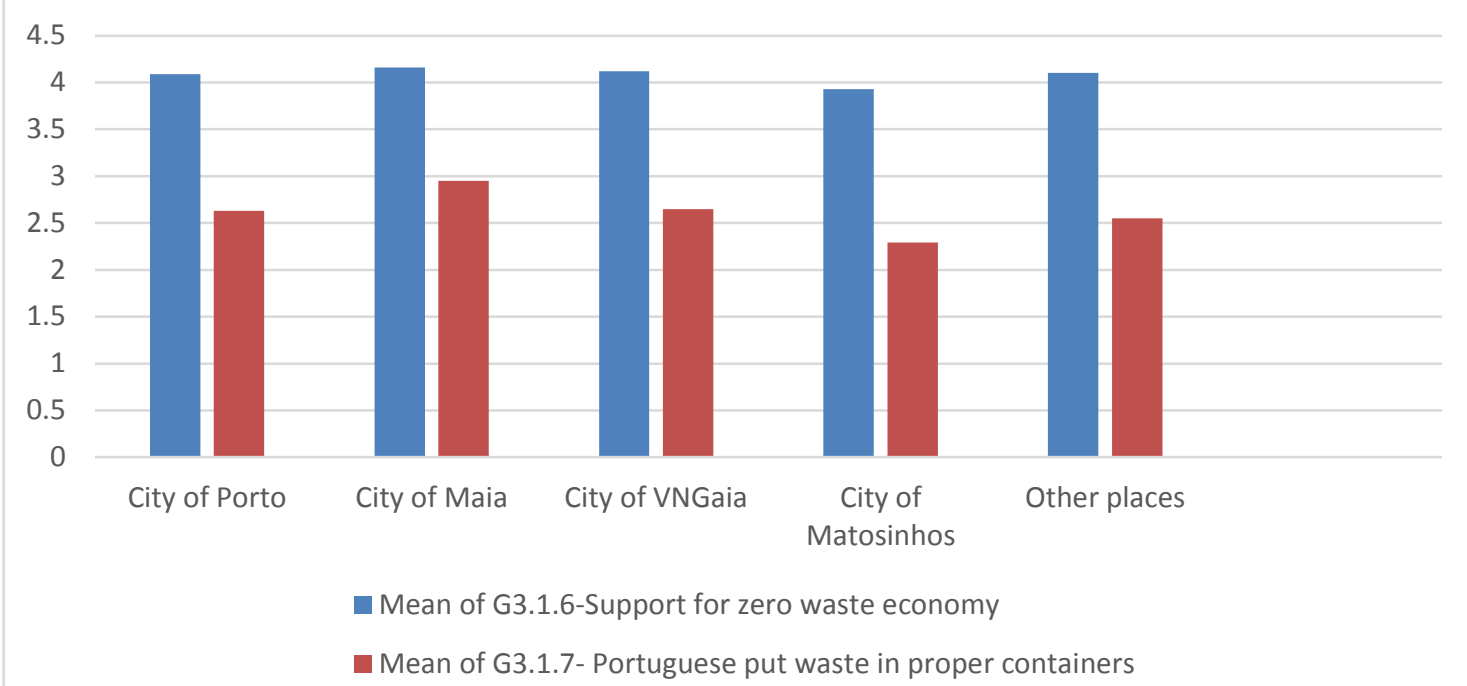

PICBE | 383

Figure 9. Respondents' support for CE and perception of CE adoption by Portuguese citizens and companies by place of residence

Source: Authors' own research.

\section{Conclusion}

To sum up, the ISEP - P. Porto population agrees that is beneficial, both to the economy and the environment, the adoption of production systems based on the reuse and/or recycling of products and parts. In addition, results suggest that selective waste collection should be the basis to produce new products and support the adoption of a "zero waste economy" where all the materials and products are reused and/or recycled, which is fully in line with Circular Economy concepts. However, they consider that most Portuguese citizens and companies only moderately deposit, segregate and manage their waste adopting the best and responsible environmental practices and that the Portuguese legislation does not strongly support their adoption. The results are similar for the different populations within Porto Metropolitan area, however, due to the low response rate, the investigation of CE and its benefits for the Portuguese society, should be pursued and reinforced. It is also recommended to strengthen Circular Economy concepts and approaches in the syllabus of ISEP's engineering courses with the goal of promoting Students as change agents for the adoption and proactively support of CE.

\section{Acknowledgements}

The authors would like to acknowledge the contribution of the respondents. CIDEM, R\&D unit is funded by the FCT - Portuguese Foundation for the Development of Science and Technology, Ministry of Science, Technology, and Higher Education, under the Project UID/EMS/0615/2016. This study had the financial support of FCT Fundação para a Ciência e Tecnologia of Portugal under the project UID/CEC/00319/2013. Pedro Domingues is supported by FCT Post-Doc Grant Reference SFRH/BPD/103322/2014. This study is 
undertaken within the framework of Portugal 2020 Project "PME Sustentável - Projeto no16129".

\section{References}

Armstrong, J.S., and Overton, T.S. (1977). Estimating Nonresponse Bias in Mail Surveys. Journal of Marketing, 14 (3), 396-402.

Bratianu, C. (2007). Thinking patterns and knowledge dynamics. In Martins, B. and Remenyi, D. (Eds.). Proceedings of the $8^{\text {th }}$ European Conference on Knowledge Management, 6-7 September 2007. Consorci Escola Industrial de Barcelona, Barcelona, Spain (pp. 152-157). Reading: Academic Conferences.

Bratianu, C. (2009). The frontier of linearity in the intellectual capital metaphor. In Stam, C. and Andriessen, D. (Eds.). Proceedings of the European Conference on Intellectual Capital (pp.97-103). Inholland University of Applied Sciences, Haarlem, The Netherlands, 28-29 April 2009. Reading: Academic Conferences and Publishing International.

Bratianu, C. and Bolisani, E. (2015). Knowledge strategies: an integrated approach for managing uncertainty. In Massaro, M. and Garlatti, A. (Eds.). Proceedings of the $16^{\text {th }}$ European Conference on Knowledge Management, University of Udine, Italy, 3-4 September 2015 (pp. 169-177). Reading: Academic Conferences and Publishing International.

Ellen Macarthur Foundation (2014). Towards the Circular Economy, vol. 3: Accelerating the scale-up across global supply chains. Cowes: Ellen Macarthur Foundation.

European Commission (2015). Closing the loop: an EU action plan for the circular economy, Communication from the Commission to the European Parliament, the Council, the European Economic and Social Committee and the Committee of the Regions. doi:10.1017/CB09781107415324.004.

European Environmental Agency (2016). Circular economy in Europe. Developing the knowledge base. doi:10.2800/51444.

Fonseca, L.M. and Domingues, J.P., (2017). How to succeed in the digital age? Monitor the organizational context, identify risks and opportunities, and manage change effectively. Management \& Marketing. Challenges for the Knowledge Society, 12(3), 443-455. DOI: $10.1515 / \mathrm{mmcks}-2017-0027$.

Fonseca, L. (2015). ISO 14001:2015: An improved tool for sustainability. Journal of Engineering and Management, 8(1), 37-50.

Domingues, J.P.T, Sampaio, P. and Arezes, P.M. (2015). Analysis of integrated management systems from various perspectives. Total Quality Management and Business Excellence, 26(11-12), 1311-1334.

Domingues, J.P.T, Sampaio, P. and Arezes, P.M. (2017). Analysis of certified occupational health and safety management systems in Portugal. International Journal of Occupational and Environmental Safety, 1(1), 11-28.

Ghisellini, P., Cialani, C. and Ulgiati, S. (2016). A review on circular economy: the expected transition to a balanced interplay of environmental and economic systems. Journal of Cleaner Production, 114, 11-32.

Geissdoerfer, M., Savaget, P., Bocken, N.P.M. and Hultink, E.J. (2017). The Circular Economy A new sustainability paradigm?. Journal of Cleaner Production, 143, 757-768. 
Lakatos, E.S., Dan, V., Cioca, L.I., Bacali, L. and Ciobanuet, A.M. (2016). How Supportive Are Romanian Consumers of the Circular Economy Concept: A Survey. Sustainability MDPI, 08(8).789.

Heshmati, A., 2016. A Review of the Circular Economy and its Implementation, Working Paper Series in Economics, and Institutions of Innovation. Royal Institute of Technology, CESIS - Centre of Excellence for Science and Innovation Studies.

Yong, L. and Bai, Y. (2016). An exploration of firms' awareness and behavior of developing circular economy: An empirical research in China. Resources, Conservation and Recycling, 87, 145-152.

Lieder, M. and Rashid, A., (2016). Towards circular economy implementation: A comprehensive review in context of manufacturing industry. Journal Cleaner Production. 115, 36-51. doi:10.1016/j.jclepro.2015.12.042.

Murray, A., Skene, K. and Haynes, K. (2017). The Circular Economy: An Interdisciplinary Exploration of the Concept and Application in a Global Context. Journal Business Ethics, 140, 369-380.

Nulty, D.D. (2008). The adequacy of response rates to online and paper surveys: what can be done? Assessment \& Evaluation in Higher Education, 33 (3), 301-314.

Pearce, D.W. and Turner, R.K. (1990). Economics of natural resources and the environment, John Hopkins University Press. Elsevier.

Sauvé, S., Bernard, S. and Sloan, P., (2016). Environmental sciences, sustainable development and circular economy: Alternative concepts for trans-disciplinary research. Environmental Development, 17, 48-56. doi:10.1016/j.envdev.2015.09.002

Zhijun, F., and Nailing, Y. (2007). Putting a circular economy into practice in China. Sustainability Science, 2(1), 95-101. doi:10. 1007/s11625-006-0018-1. 